\title{
Urgences dermatologiques en réanimation : infections nécrosantes de la peau et des parties molles et toxidermies graves
}

\section{Dermatological Emergencies in the Intensive Care Unit: Necrotizing Skin and Soft Tissue Infections and Severe Cutaneous Adverse Reactions}

\author{
T. Urbina $\cdot$ C. Hua $\cdot$ E. Sbidian $\cdot$ S. Ingen-Housz-Oro $\cdot$ T.-A. Duong $\cdot$ P. Wolkenstein $\cdot$ R. Bosc $\cdot$ K. Razazi $\cdot$ \\ G. Carteaux $\cdot$ O. Chosidow $\cdot$ A. Mekontso Dessap $\cdot$ N. de Prost \\ (C) SRLF et Lavoisier SAS 2018
}

Résumé Les urgences dermatologiques nécessitant une admission en réanimation sont rares mais associées à une mortalité élevée et à de lourdes séquelles à long terme. Elles sont essentiellement représentées par les infections

T. Urbina · K. Razazi · G. Carteaux · A. Mekontso Dessap ·

N. de Prost $(\bowtie)$

Service de réanimation médicale,

hôpitaux universitaires Henri-Mondor-Albert-Chenevier,

Assistance publique-Hôpitaux de Paris (AP-HP),

F-94010 Créteil, France

e-mail : nicolas.de-prost@aphp.fr

K. Razazi - G. Carteaux · A. Mekontso Dessap · N. de Prost Groupe de recherche clinique CARMAS,

faculté de médecine de Créteil, université Paris-Est-Créteil,

F-94010 Créteil, France

C. Hua $\cdot$ E. Sbidian $\cdot$ S. Ingen-Housz-Oro - T.-A. Duong

P. Wolkenstein $\cdot$ O. Chosidow $\cdot$ N. de Prost

Service de dermatologie,

Assistance publique-Hôpitaux de Paris,

hôpitaux universitaires Henri-Mondor, DHU A-TVB,

51, avenue du Maréchal-de-Lattre-de-Tassigny,

F-94010 Créteil, France,

S. Ingen-Housz-Oro · T.-A. Duong · P. Wolkenstein

O. Chosidow $\cdot$ N. de Prost

Centre national de référence maladie rare,

dermatoses bulleuses toxiques

Assistance publique-Hôpitaux de Paris,

Service de dermatologie, hôpitaux universitaires

Henri-Mondor, DHU A-TVB,

51, avenue du Maréchal-de-Lattre-de-Tassigny,

F-94010 Créteil, France,

R. Bosc

Service de chirurgie plastique et reconstructrice,

Assistance publique-Hôpitaux de Paris,

hôpitaux universitaires Henri-Mondor, DHU A-TVB,

51, avenue du Maréchal-de-Lattre-de-Tassigny,

F-94010 Créteil, France,

Reçu le 19 mai 2018 ; accepté le 8 juillet 2018 nécrosantes des tissus mous (également appelées : dermohypodermites bactériennes nécrosantes-fasciites nécrosantes [DHBN-FN]) et par les toxidermies graves que sont les nécrolyses épidermiques (comprenant le syndrome de Lyell ou nécrolyse épidermique toxique [NET], le syndrome de Stevens-Johnson [SJS] et le DRESS (drug reaction with eosinophilia and systemic symptoms)). Elles ont pour caractéristiques communes un diagnostic souvent difficile, la nécessité d'une approche multidisciplinaire et de soins paramédicaux lourds et spécifiques, imposant fréquemment le transfert dans un centre expert. Le traitement des DHBN-FN est médicochirurgical, associant un débridement chirurgical précoce et une antibiothérapie probabiliste à large spectre. La présence de signes de gravité locaux (nécrose, crépitation, douleur intense) ou généraux (sepsis, choc septique) est une indication d'urgence à l'exploration chirurgicale. Sa précocité est le principal facteur pronostique modifiable, les recommandations de thérapeutiques complémentaires (immunoglobulines intraveineuses, oxygénothérapie hyperbare, pansement à pressions négatives, ...) reposant à ce jour sur un faible niveau de preuve. L'élément essentiel de la prise en charge des toxidermies graves est la recherche et l'arrêt du médicament imputable, facteur essentiel du pronostic. Le SJS et le NET, en général associés à une ou plusieurs atteintes muqueuses, entraînent dans les formes les plus graves une défaillance cutanée aiguë. La prise en charge repose sur les soins de support (correction des troubles hydroélectrolytiques, prévention de l'hypothermie, prévention et traitement des épisodes infectieux, analgésie et anxiolyse, soins locaux). Les complications infectieuses et respiratoires sont les principales causes de décès à la phase aiguë. Aucun traitement spécifique n'a fait la preuve de son efficacité à ce jour. Le diagnostic de DRESS est difficile, et la prise en charge doit être multidisciplinaire. Sa gravité tient aux possibles atteintes viscérales associées (hépatique, rénale et cardiaque) qui justifient dans les formes graves d'une corticothérapie urgente. 
Mots clés Toxidermie $\cdot$ Infection nécrosante de la peau et des parties molles $\cdot$ Fasciite nécrosante $\cdot$ Nécrolyse épidermique · Syndrome de Lyell · DRESS · Réanimation

\begin{abstract}
Dermatological emergencies are a rare cause of intensive care unit admission but are associated with a high mortality rate and a high risk of long-term sequelae for survivors. They predominantly consist of necrotizing soft tissue infections (NSTI) and severe cutaneous adverse reactions (SCARs), including toxic epidermal necrolysis (TEN), Stevens-Johnson syndrome (SJS) and the drug reaction with eosinophilia and systemic symptoms (DRESS) syndrome. These diseases are often difficult to diagnose and require a pluridisciplinary approach together with heavy and specific nurse care, frequently leading to transfer to expert centers. NSTI management during the early phase combines a surgical debridement of all infected tissues and the prompt initiation of a broad-spectrum empiric antibiotherapy. Presence of severity signs whether local (necrosis, crepitations, intense pain) or general (sepsis/septic shock) should prompt urgent surgical exploration. It's readiness is the main modifiable prognostic factor, guidelines on adjunctive therapies (intravenous immunoglobulins, hyperbaric oxygen, negative pressure wound dressings, ...) being to date based on weak evidence. The key initial step of SCARs management is the identification and removal of all culprit drugs. TEN management is mainly supportive and includes the correction of dehydration and associated metabolic disorders, hypothermia prevention, prevention and treatment of infections, analgesia, anxiolysis and skin care. Infectious and respiratory complications are the main cause of death during the acute phase. No specific treatment has proven its efficacy. The diagnosis of DRESS syndrome may be difficult and its management should involve a multidisciplinary team, depending on the clinical presentation. Severity is related to possible organ involvement (cardiac, hepatic, and renal).
\end{abstract}

Abréviations
DHBN-FN : dermohypodermite bactérienne nécrosante-fasciite
nécrosante
NET : nécrolyse épidermique toxique
SJS : syndrome de Stevens-Johnson
DRESS : drug reaction with systemic symptoms
IRM : imagerie par résonance magnétique
IgIV : immunoglobulines polyvalentes intraveineuses
TPN : traitement des plaies par pression négative
IDSA : Infectious Diseases Society of America
SPILF : Société de pathologie infectieuse de langue française
ISAC : International Society of Antimicrobial Chemotherapy

Treatment of the most severe forms relies on immunosuppression (systemic corticosteroids).

Keywords Severe cutaneous adverse reactions . Necrotizing skin and soft tissue infections - Epidermal necrolysis $\cdot$ DRESS $\cdot$ Intensive care $\cdot$ Necrotizing fasciitis

\section{Introduction}

Les urgences dermatologiques nécessitant une admission en réanimation comportent principalement les infections nécrosantes de la peau et des parties molles ou dermohypodermites bactériennes nécrosantes-fasciites nécrosantes (DHBNFN) et les toxidermies graves, principalement nécrolyse épidermique (nécrolyse épidermique toxique [NET] et syndrome de Stevens-Johnson [SJS]) et DRESS (drug reaction with eosinophilia and systemic symptoms). Elles représentaient $0,5 \%$ des admissions en réanimation, soit 2,1 admissions/réanimation par an dans une large base de données britannique [1]. Ces urgences dermatologiques ont en commun leur sévérité, avec une mortalité élevée et un haut risque de séquelles fonctionnelles, leur rareté, à l'origine d'un retard diagnostique et thérapeutique fréquent, et enfin la lourdeur et la spécificité des soins paramédicaux nécessaires à leur prise en charge, justifiant souvent le transfert en milieu spécialisé.

L'objectif de cette revue est d'exposer de manière pragmatique les modalités de diagnostic et de prise en charge de ces urgences dermatologiques, infectieuses ou non, pouvant nécessiter une admission en réanimation. D'autres maladies ayant une expression cutanée parfois au premier plan, telles que le purpura fulminans infectieux, les réactions anaphylactiques graves ou encore les vascularites nécrosantes, sont également des motifs d'admissions « dermatologiques » en réanimation, mais ne seront pas abordées dans le cadre de cette revue générale.

\section{Infections nécrosantes de la peau et des parties molles (à l'exclusion du patient neutropénique)}

\section{Données épidémiologiques}

Les DHBN-FN sont des infections rares, dont l'incidence est estimée à 4/100 000 habitants par an aux États-Unis, associées à une mortalité importante, variant de 25 à $50 \%$ selon les études [2,3]. Les facteurs de risque connus sont l'âge supérieur à 60 ans, le sexe masculin, l'obésité, le diabète, la consommation d'alcool, l'insuffisance rénale, les hépatopathies et l'immunosuppression, dont les néoplasies et la corticothérapie [4]. Il faut ajouter à cela les facteurs locaux 
comme les plaies chroniques, les lésions préexistantes et les injections ou piqûres. Une DHBN-FN peut néanmoins survenir même en l'absence de facteur de risque, et des cas ont été décrits à la suite de traumatismes fermés [5]. La prise d'anti-inflammatoires non stéroïdiens (AINS) entraine probablement un retard de prise en charge en diminuant l'intensité initiale des symptômes. Plusieurs séries rapportent l'utilisation fréquente d'AINS à la phase initiale des DHBN-FN, plus souvent dans les localisations cervicofaciales et généralement quand le diagnostic n'est pas encore établi, mais il est difficile de conclure à une causalité entre l'aggravation de l'infection et l'exposition aux AINS [6]. L'association entre des formes graves de DHBN-FN, notamment à streptocoque ou à staphylocoque, et la prise d'AINS justifie certainement leur contre-indication dès la suspicion clinique de DHBNFN $[7,8]$.

Les principaux déterminants de la mortalité sont l'âge, les comorbidités, l'atteinte multifocale ou nosocomiale ainsi que la présence d'un choc septique à l'admission [9]. Les principaux facteurs pronostiques modifiables sont la précocité du débridement chirurgical et celle de l'antibiothérapie efficace [10].

\section{Diagnostic}

\section{Présentation clinique}

Les DHBN-FN intéressent les membres, généralement inférieurs, dans $70 \%$ des cas environ. Les autres formes cliniques sont les DHBN-FN abdominopérinéales, cervicothoraciques (généralement d'origine dentaire) et orbitaires qui nécessitent une prise en charge en centre spécialisé. Du fait de la variété des terrains sous-jacents, des localisations et des agents infectieux, les présentations cliniques peuvent être très diverses (Fig. 1). Les signes cutanés évocateurs sont, outre l'érythème et l'œdème communs aux dermohypodermites non nécrosantes, la présence de zones cyaniques, livédoïdes, bulleuses, nécrotiques parfois hémorragiques, une hypoesthésie, une crépitation et une douleur intense. L'extension rapide des lésions, a fortiori sous antibiothérapie bien conduite, évaluée par une délimitation pluriquotidienne du placard inflammatoire, est un élément en faveur du diagnostic de DHBN-FN, par opposition au diagnostic d'érysipèle. Ce d'autant plus que les signes cliniques les plus francs (c'est-à-dire zones cutanées nécrotiques, bulles et crépitation sous-cutanée) sont inconstants au stade précoce, comme en témoigne une étude récente où ils n'étaient retrouvés que dans respectivement 23,44 et $5 \%$ des cas (Tableau 1). Leur absence ne doit en aucun cas faire écarter le diagnostic. Environ la moitié des patients présentent des signes de retentissement systémique (sepsis ou choc septique). Les recommandations internationales suggèrent que toute infection cutanée associée à une ou plusieurs défaillances d'organes,

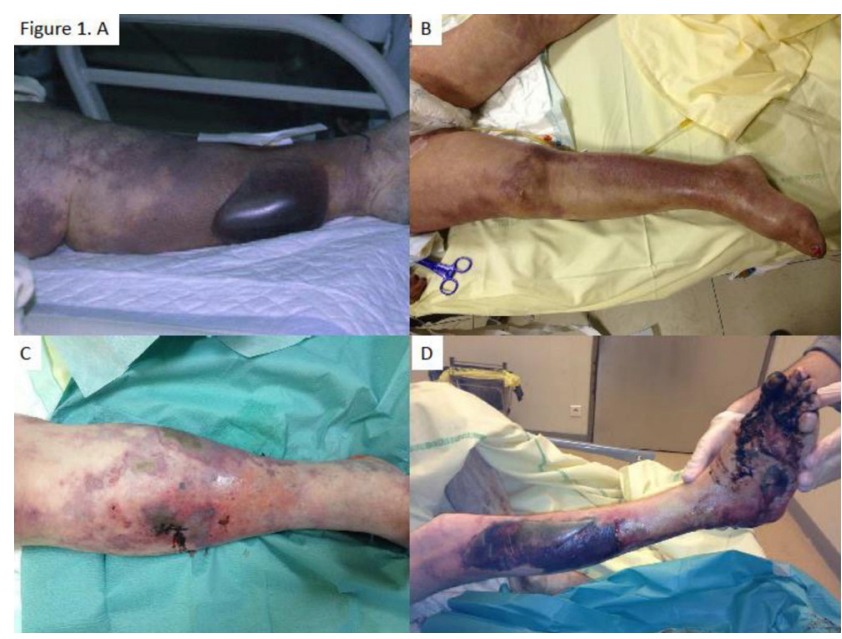

Fig. 1 Sémiologie des dermohypodermites nécrosantes de la peau et des parties molles des membres. A. Aspect livédoïde et cyanique de la jambe avec volumineuse bulle hémorragique de la face postérieure. B. Aspect livédoïde du membre inférieur droit avec œdème du pied. C. Zones cyaniques et livédoïdes du membre inférieur chez le même patient que la photographie $\mathrm{B}$, après 12 heures d'évolution. On note un aspect de nécrose cutanée plurifocale, notamment visible autour d'une incision exploratoire réalisée à visée diagnostique. D. Nécrose ischémique du pied, érythème et pâleur cutanée du pied et de la jambe et volumineuse phlyctène hématique en partie affaissée de la face antéroexterne de la jambe

Tableau 1 Fréquence des signes cutanés au cours des infections nécrosantes de la peau et des parties molles (adapté de Kiat et al. [11])

\begin{tabular}{|ll|}
\hline Signes cutanés & Fréquence (\%) \\
\hline Douleur & 77 \\
Érythème & 70 \\
Edème & 70 \\
Bulles & 44 \\
Nécrose cutanée & 23 \\
Crépitation & 5 \\
\hline
\end{tabular}

ou s'aggravant brutalement, doit faire considérer le diagnostic d'infection nécrosante, même en l'absence de signe local de gravité [12].

La confirmation diagnostique repose sur la constatation peropératoire de tissus atones, parfois nécrotiques, se décollant facilement au doigt et la présence d'un exsudat caractéristique en " eau de vaisselle », nauséabond. Le chirurgien constatera une nécrose du derme et de l'hypoderme qui sera isolée ou associée à une nécrose du fascia, voire du muscle. Hormis la confirmation du diagnostic d'infection nécrosante, ces constatations opératoires ne modifient pas la stratégie générale de prise en charge. En cas de doute, et pour éviter 
de réaliser un geste chirurgical inutilement délabrant, l'association de l'examen extemporané de biopsies tissulaires et d'un examen direct bactériologique peut s'avérer utile [13].

Pour certaines formes cliniques de DHBN-FN, il est crucial de préciser la porte d'entrée, car elle conditionnera en partie la prise en charge. Ainsi, les DHBN-FN abdominopérinéales ont généralement une origine digestive, urinaire ou périnéogénitale ( « gangrène de Fournier ») et peuvent nécessiter une colostomie pour éviter la contamination du site opératoire par des selles. Les DHBN cervicofaciales ont une origine dentaire ou pharyngée dans respectivement 50 et $20 \%$ des cas. Une extension médiastinale, présente dans $30 \%$ des cas, associée à une surmortalité et pouvant nécessiter un drainage est également à rechercher systématiquement [14].

\section{Examens paracliniques}

Il n'existe pas d'examen paraclinique permettant de retenir ou d'éliminer avec certitude le diagnostic de DHBN-FN. Ces examens ne doivent jamais se substituer à l'exploration chirurgicale en cas de forte suspicion clinique.

Un score composite (le Laboratory Risk Indicator for Necrotizing Fascitis [LRINEC]) comportant six variables biologiques de routine (CRP, leucocytes, natrémie, hémoglobine, créatininémie, glycémie) a été proposé comme aide pour distinguer infections cutanées nécrosantes et non nécrosantes. La littérature est discordante quant à ses performances diagnostiques réelles, et il semble clair qu'un score bas ne doive certainement pas faire surseoir à une exploration chirurgicale en cas de suspicion clinique élevée de DHBNFN $[15,16]$. L'élévation de la créatinine-kinase et celle du lactate artériel ont été associées au diagnostic de DHBNFN dans des cohortes à effectif limité $[17,18]$. Cependant, aucun biomarqueur de DHBN-FN n'a de performance diagnostique lui permettant d'être intégré dans un algorithme de prise en charge.

Concernant les examens radiologiques, l'imagerie par résonance magnétique (IRM) peut être utile pour les DHBN-FN des membres ayant une présentation clinique douteuse et bien sûr en l'absence de signe clinique de gravité (sepsis, choc septique) [19]. Des anomalies de signal ou un épaississement du fascia musculaire en utilisant des séquences en « suppression de graisse » et l'absence de rehaussement du fascia après injection de produit de contraste semblent suggérer une probabilité élevée de DHBN-FN [20]. Le scanner a peu d'intérêt pour les DHBN-FN des membres, hormis celui de mettre en évidence des bulles d'air dans $10 \%$ des cas environ, et peut même être faussement rassurant. En revanche, il est indispensable pour les DHBN-FN abdominopérinéales et cervicofaciales, car il permet souvent de documenter la porte d'entrée ou l'extension — notamment médiastinale - de l'infection, comme discuté plus haut.

\section{Exploration microchirurgicale au lit du malade (finger test)}

En cas de doute diagnostique faisant remettre en cause la nécessité d'une prise en charge au bloc opératoire, il est possible de réaliser un finger test. Celui-ci ne doit en aucun cas être une simple ponction à l'aiguille qui se voudrait rassurante en cas de saignement. Il consiste en une véritable exploration microchirurgicale au lit du malade. Après avoir réalisé une anesthésie locale et une incision de $2 \mathrm{~cm}$ jusqu'au fascia musculaire, on recherchera une atonie tissulaire, l'absence de saignement, un exsudat nauséabond et surtout un décollement aisé du fascia au doigt [21]. Si l'un de ces signes est présent, il fournit un argument supplémentaire pour un débridement chirurgical extensif en urgence au bloc opératoire.

\section{Microbiologie}

\section{Prélèvements}

Hormis les hémocultures, positives dans $25 \%$ des cas environ, la culture de fragments de biopsie cutanée et du liquide de ponction-aspiration sous-cutanée à l'aiguille est recommandée par l'IDSA (Infectious Diseases Society of America), notamment en cas d'immunosuppression [22]. La ponction-aspiration sous-cutanée consiste à injecter $1 \mathrm{ml}$ de soluté salé isotonique en sous-cutané puis à réaspirer pour mettre le liquide en culture. Ses performances diagnostiques n'ont pas été bien évaluées dans les DHBN-FN, mais les experts s'accordent sur le fait qu'une culture positive a une bonne valeur diagnostique. La ponction de phlyctène est également simple à réaliser. Des prélèvements peropératoires multiples seront envoyés en bactériologie pour tous les patients, et en mycologie chez les patients immunodéprimés, diabétiques, ayant subi un traumatisme sévère et/ou avec souillure tellurique ou présentant une infection autour d'un site d'injection $[23,24]$.

\section{Agents pathogènes}

On retrouve une documentation microbiologique dans environ $90 \%$ des cas, avec en moyenne un tiers d'infections monomicrobiennes et deux tiers d'infections polymicrobiennes [25]. Streptococcus pyogenes est mis en évidence dans plus de la moitié des cas monomicrobiens et dans un tiers des cas polymicrobiens [9]. Les infections polymicrobiennes retrouvent essentiellement des entérobactéries, des bacilles à Gram négatif non fermentants et des cocci à Gram positif. Enfin, les tableaux de « gangrène » sont volontiers associés à des germes anaérobies du genre Clostridium. Les infections fongiques, plus rares, sont essentiellement l'apanage des patients immunodéprimés, ayant subi des traumatismes sévères ou présentant une infection autour d'un site d'injection. 
Prise en charge à la phase aiguë

Une récente enquête dans les réanimations européennes montrait une grande hétérogénéité des pratiques concernant la prise en charge des DHBN-FN [26]. Elle soulignait les différences entre les équipes prenant en charge plus ou moins de trois DHBN-FN par an, en termes de disponibilité d'experts dermatologues, chirurgiens ou réanimateurs, mais aussi concernant le plateau technique disponible. Pour les réanimateurs interrogés, les principaux éléments participant au retard de prise en charge étaient le retard diagnostique, le retard à la décision chirurgicale et les difficultés d'accès au bloc opératoire. Ces données soulignaient la nécessité d'homogénéiser les pratiques et le potentiel intérêt de désigner des « référents » dans chaque spécialité impliquée, voire de recourir à des centres experts pour améliorer la prise en charge et le pronostic de ces patients. Les éléments essentiels sont un traitement chirurgical précoce et répété si besoin, associé à une antibiothérapie à large spectre et à la prise en charge des éventuelles défaillances d'organes. L'élaboration d'un circuit dédié aux
DHBN-FN reposant sur un algorithme simplifié peut certainement permettre d'améliorer la prise en charge des patients et notamment de fluidifier l'accès au bloc opératoire (Fig. 2).

\section{Chirurgie}

La précocité du traitement chirurgical est l'un des principaux facteurs pronostiques modifiables [10]. L'objectif de la chirurgie à la phase aiguë est de réaliser un débridement rapide et complet de tous les tissus nécrotiques ou infectés. Le premier débridement est considéré par les experts comme étant un geste de chirurgie générale [27]. Une réévaluation au bloc opératoire 24 heures après le premier débridement (c'està-dire second-look) est recommandée à la recherche de tissus nécrotiques résiduels. Des chirurgies séquentielles sont en effet souvent nécessaires, et le nombre moyen de débridements réalisés est généralement de l'ordre de deux à quatre [28]. L'absence d'amélioration ou la réaggravation clinique du patient doivent faire discuter une nouvelle exploration chirurgicale [29].

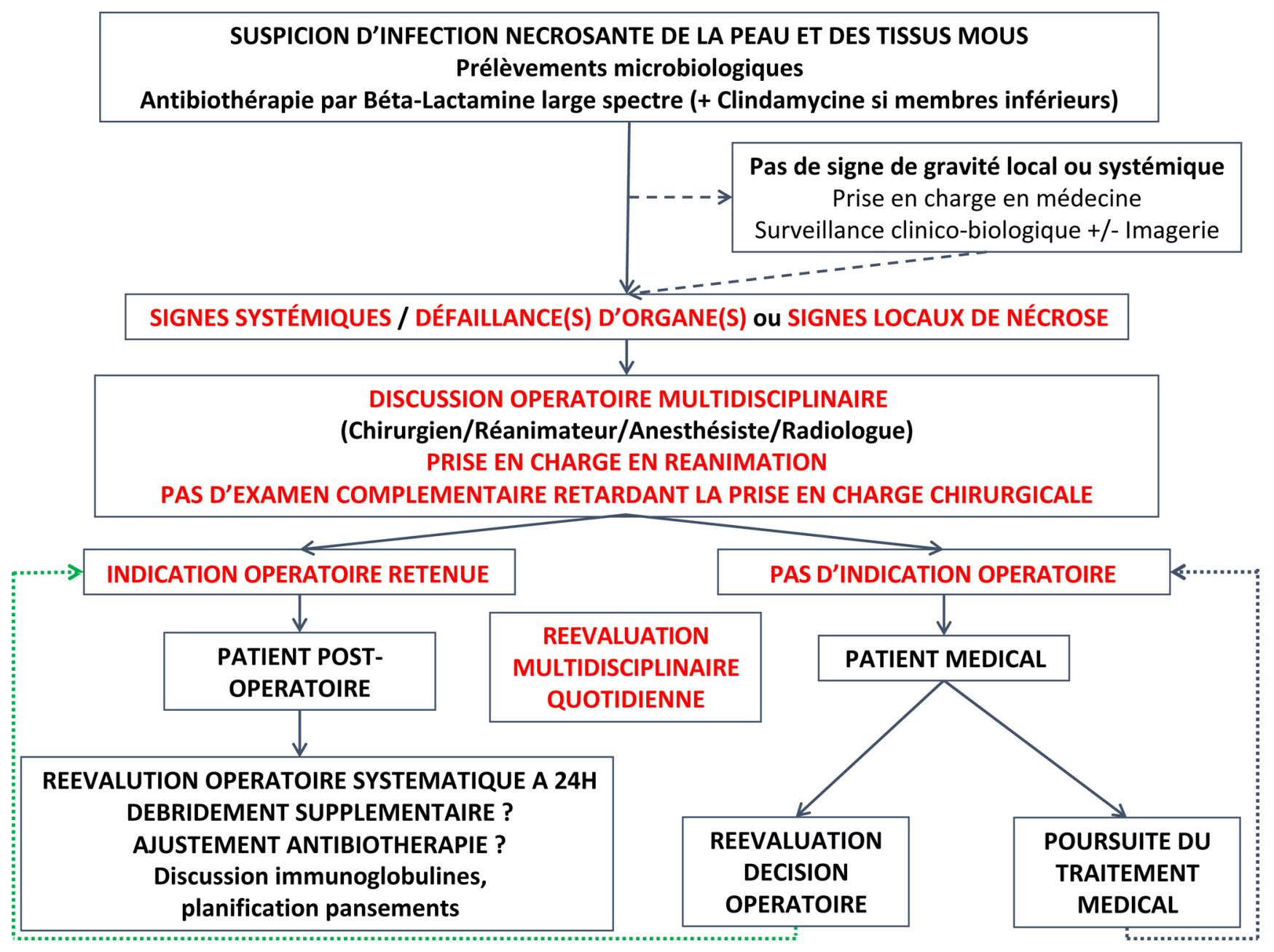

Fig. 2 Proposition d'algorithme de prise en charge des dermohypodermites nécrosantes de la peau et des parties molles 
La question d'un transfert systématique des patients vers des centres « experts », c'est-à-dire ayant un plateau technique adapté et un volume d'activité élevé, a été posée par certains auteurs. La prise en charge par une équipe médicochirurgicale entraînée pourrait être associée à un meilleur pronostic [30]. Une récente étude rétrospective française a montré que la mortalité dans les centres prenant en charge au moins trois DHBN-FN par an était inférieure à celle observée dans les centres ayant un volume d'activité moindre [31]. Ces données sont bien évidemment à mettre en balance avec le risque de retard au premier geste chirurgical potentiellement associé à un transfert interhospitalier [27,32]. Le transfert en centre expert est ainsi probablement bénéfique, sous réserve qu'il n'induise pas un délai de prise en charge significatif (plusieurs heures). Dans le cas contraire, l'idéal est probablement d'effectuer le premier débridement sur place et d'envisager le transfert dans un second temps.

Les conséquences à long terme chez les patients survivant à la phase aiguë sont majeures, à la fois en ce qui concerne la diminution de leur espérance de vie mais aussi leur qualité de vie physique et mentale [33]. L'impact de l'autonomie antérieure et des comorbidités associées sur la qualité de vie à long terme n'a pas été évalué, mais il semble clair que l'âge n'est pas le seul facteur à prendre en compte. Ainsi, le nombre de chirurgies nécessaires comme la surface de tégument débridée étaient corrélés à la qualité de vie ultérieure dans une étude récente. Ces éléments doivent donc être intégrés dans les décisions d'intervention et surtout de réintervention et peuvent conduire à prendre des décisions de limitation de soins [33].

\section{Antibiothérapie}

Une antibiothérapie probabiliste à large spectre active à la fois sur les bactéries à Gram positif, à Gram négatif et anaérobies doit être débutée sans délai, une fois le diagnostic de DHBN-FN suspecté $[12,22,34]$. L'antibiothérapie probabiliste recommandée est une bêta-lactamine à large spectre (Tableau 2), en pratique l'association pipéracilline-tazobactam, en conservant les indications classiques à une bithérapie avec un aminoside (choc septique essentiellement) [24]. Seules les infections cervicofaciales sont associées à une proportion suffisante de germes sensibles à l'association amoxicilline-clavulanate pour recommander son utilisation [14]. On associera de la clindamycine à l'antibiothérapie initiale dans les formes avec suspicion d'infection streptococcique (c'est-à-dire DHBN-FN avec signes systémiques compatibles avec un syndrome de choc toxinique) [22]. La clindamycine a en effet montré une activité antitoxinique in vitro [35], et il existe un bénéfice dans plusieurs séries observationnelles à l'association bêta-

lactamine-clindamycine versus bêta-lactamine seule pour la prise en charge des infections invasives à streptocoque $\mathrm{A}$ $[22,36]$. Elle ne doit cependant pas être utilisée en monothérapie. Du fait de la faible prévalence de staphylocoques dorés résistants à la méticilline en France, et bien que recommandée aux États-Unis [22], l'adjonction systématique d'un glycopeptide ou d'une oxazolidinone peut être réservée aux patients présentant une colonisation connue ou des facteurs de risque de portage (long séjour, hospitalisation en soins de suite-réadaptation, hémodialyse chronique) [34].

Tableau 2 Antibiothérapie probabiliste au cours des infections de la peau et des parties molles (adapté des recommandations de l'IDSA 2014 [22], SPILF 2000 [34] et du consensus d'experts de l'ISAC 2018 [24])

\begin{tabular}{|c|c|c|}
\hline Localisation & Antibiothérapie de $1^{\text {re }}$ intention & En cas d'allergie à la pénicilline \\
\hline Membres inférieurs & $\begin{array}{l}\cdot \text { Pipéracilline-tazobactam } \\
\cdot+\text { Clindamycine } \\
\cdot \pm \text { Vancomycine }^{\mathrm{a}} \text { ou linézolide } \\
\cdot \pm \text { Aminoside }^{\mathrm{a}, \mathrm{b}}\end{array}$ & $\begin{array}{l}\cdot \text { Aztréonam } \\
\cdot+\text { Vancomycine ou linézolide ou daptomycine } \\
\cdot \pm \text { Aminoside }^{\mathrm{c}}\end{array}$ \\
\hline Cervicofaciale & $\begin{array}{l}\cdot \text { Amoxicilline-acide clavulanique }^{\mathrm{d}} \\
\cdot+\text { Clindamycine }^{\mathrm{a}} \\
\cdot \pm \text { Aminoside }^{\mathrm{c}}\end{array}$ & $\begin{array}{l}\text { - Vancomycine ou linézolide ou daptomycine } \\
\text { - + Clindamycine } \\
\text { - } \pm \text { Aminoside }^{\mathrm{c}}\end{array}$ \\
\hline Abdominopérinéale & $\begin{array}{l}\text { - Pipéracilline-tazobactam ou imipénème-- } \\
\text { cilastatine } \\
\text { - } \pm \text { Aminoside }^{\mathrm{c}}\end{array}$ & $\begin{array}{l}\cdot \text { Vancomycine ou linézolide } \\
\cdot+\text { Aztréonam } \\
\cdot+\text { Métronidazole } \\
\text { • } \pm \text { Aminoside }\end{array}$ \\
\hline \multicolumn{3}{|c|}{$\begin{array}{l}{ }^{a} \text { La couverture du Staphylococcus aureus résistant à la méticilline (SARM) pour les DHBN-FN nosocomiales sera à discuter en fonc- } \\
\text { tion des facteurs de risque de SARM (long séjour, SSR, hémodialyse chronique, portage de SARM connu) } \\
\text { b Le linézolide permet de s'affranchir de la clindamycine } \\
{ }^{\mathrm{c}} \text { Si choc } \\
{ }^{\mathrm{d}} \text { Peut se justifier du fait de la très fréquente sensibilité des germes associés aux formes cervicofaciales }\end{array}$} \\
\hline
\end{tabular}


De la même façon, l'utilisation de carbapénèmes doit être réservée aux situations nosocomiales avec colonisation connue ou facteurs de risque de portage de bêta-lactamase à spectre étendu. En cas d'allergie grave aux bêta-lactamines, on proposera un traitement par vancomycine ou linézolide en combinaison avec aztréonam et clindamycine ou métronidazole. L'antibiothérapie sera secondairement adaptée aux documentations microbiologiques. La durée de traitement n'a fait l'objet d'aucune étude ou recommandation, mais il est suggéré de maintenir le traitement jusqu'à 48-72 heures après stabilisation clinique, pour une durée totale comprise entre 7 et 15 jours [29].

\section{Immunoglobulines polyvalentes intraveineuses}

Les immunoglobulines intraveineuses (IgIV) ont montré un bénéfice sur la mortalité chez des patients présentant un choc toxique streptococcique, dont $60 \%$ présentaient une infection de la peau et des parties molles [37-39]. Cependant, l'analyse récente d'une large cohorte rétrospective de plus de 4000 patients pris en charge pour une DHBN-FN avec choc septique concluait à l'absence d'impact des IgIV sur la mortalité hospitalière [40]. Une étude randomisée contrôlée ne retrouvait pas non plus de bénéfice des IgIV [41], même s'il faut noter que cette étude souffrait d'une très faible proportion d'infections streptococciques et staphylococciques et testait des doses d'IgIV inférieures aux doses habituellement recommandées. Au total, la disparité des données existantes a abouti à l'absence de recommandation concernant les IgIV par l'IDSA [22], malgré l'avis favorable d'un groupe d'experts dans les formes sévères de DHBN-FN à streptocoque ou à staphylocoque [24]. La posologie employée dans les essais sur le choc toxique streptococcique était de $1 \mathrm{~g} / \mathrm{kg}$ le premier jour puis de $0,5 \mathrm{~g} / \mathrm{kg}$ les deux jours suivants. En pratique, l'utilisation des IgIV sera évaluée au cas par cas chez les patients ayant une forme sévère de DHBN-FN, avec une forte suspicion d'infection streptococcique, avec un état de choc ou des défaillances d'organes persistant malgré une prise en charge bien conduite.

\section{Oxygénothérapie hyperbare}

Il n'existe aucun essai randomisé contrôlé évaluant l'efficacité de l'oxygénothérapie hyperbare dans les infections sévères de la peau et des tissus mous. La littérature, comprenant exclusivement des études observationnelles, est discordante quant au bénéfice de cette méthode sur la mortalité [42-44], avec un possible intérêt dans la cicatrisation. Cette technique ne figure pas dans les recommandations les plus récentes, et il semble qu'un transfert vers un centre disposant spécifiquement de l'oxygénothérapie hyperbare ne doive pas venir ralentir la prise en charge chirurgicale $[12,22,24,34]$.

\section{Soins paramédicaux et mesures adjuvantes}

Les soins paramédicaux sont un élément clé de la prise en charge des DHBN-FN. Pendant la phase initiale, des pansements quotidiens sont réalisés afin de favoriser la détersion de la plaie. On utilise volontiers des pansements de la classe des alginates. Lorsque le contrôle local de l'infection a été obtenu, généralement après 7 à 15 jours, l'objectif des soins locaux (détersion mécanique et chimique au cours de pansements quotidiens) est de préparer la plaie à un recouvrement par greffe de peau. Cette dernière est réalisée après obtention d'un tissu de granulation au niveau de la plaie opératoire. Le traitement des plaies par pression négative (TPN) est une alternative à ces pansements quotidiens, mais repose sur un niveau de preuve faible dans les DHBN-FN [24,45]. Quelles que soient les modalités de pansement réalisées, on veillera à assurer une analgésie efficace et un support nutritionnel approprié afin de ne pas retarder la cicatrisation. La porte d'entrée devra être traitée. Un rappel de la vaccination antitétanique éventuellement associé à une sérothérapie sera réalisé si nécessaire.

\section{Toxidermies graves}

Les toxidermies graves sont des effets indésirables médicamenteux qui exposent à une mortalité importante à la phase aiguë et à des risques de séquelles à long terme. La première étape de prise en charge est, dès le stade de la suspicion diagnostique, de s'assurer de l'arrêt immédiat de tous les traitements imputables. La prise en charge est multidisciplinaire et doit faire intervenir dermatologues, réanimateurs, spécialistes d'organe, pathologistes et équipes de pharmacovigilance. La rareté et la gravité de ces toxidermies font recommander leur prise en charge dans des centres experts [46]. Celle-ci est essentiellement symptomatique, centrée sur la prévention de la morbimortalité aiguë mais aussi des séquelles à long terme.

Les deux principales toxidermies graves sont les nécrolyses épidermiques (syndrome de Lyell ou NET lorsque la surface cutanée décollée/décollable excède $30 \%$, SJS en dessous de $10 \%$ et syndrome de chevauchement entre 10 et $29 \%$ ) et le DRESS syndrome. Ce sont des maladies rares, dont l'incidence est de deux par million d'habitants pour le SJS/NET et d'un par 1000 à 10000 nouveaux utilisateurs d'antiépileptique pour le DRESS. Tous les médicaments peuvent être associés à ces toxidermies, mais les plus fréquents sont les antiépileptiques aromatiques, la lamotrigine, l'allopurinol et les sulfamides antibactériens $[47,48]$. Les autres toxidermies, souvent moins sévères ou plus anecdotiques ne seront pas abordées dans cette revue et comprennent principalement la pustulose exanthématique aiguë généralisée, l'érythème 
maculopapuleux, l'érythème pigmenté fixe et la dermatose à IgA linéaire [48].

Un algorithme diagnostique initial est proposé sur la figure 3 .

Nécrolyse épidermique toxique et syndrome de StevensJohnson

\section{Épidémiologie et physiopathologie}

Les SJS/NET surviennent 4 à 28 jours après une exposition médicamenteuse. Ils sont caractérisés par un décollement épithélial cutanéomuqueux extensif (Fig. 4). Le diagnostic est clinicopathologique, avec une nécrose panépidermique en histologie et une immunofluorescence directe négative. La mortalité est élevée et en partie dépendante du pourcentage de décollement cutané à la phase aiguë : $10 \%$ pour le SJS et $40 \%$ pour la NET. Elle est essentiellement liée aux infections secondaires et peut être prédite à la phase aiguë par le Toxic Epidermal Necrolysis-Specific Severity of Illness Score (SCORTEN), score en sept points cliniques et biologiques à l'admission [49]. L'atteinte de l'épithélium respiratoire est grevée d'un pronostic sombre. D'autres atteintes spécifiques d'organes existent (tube digestif, rein), mais sont plus rares. La prise en charge des SJS/NET en réanimation se rapproche de celle des patients brûlés du fait de l'existence d'une défaillance cutanée aiguë et des complications qui en découlent.

\section{Prise en charge}

- Mesures générales

L'atteinte de la barrière cutanée a des conséquences hémodynamiques (augmentation du débit sanguin cutané pouvant atteindre 5 à $10 \mathrm{l} / \mathrm{min}$ et élévation réactionnelle du débit

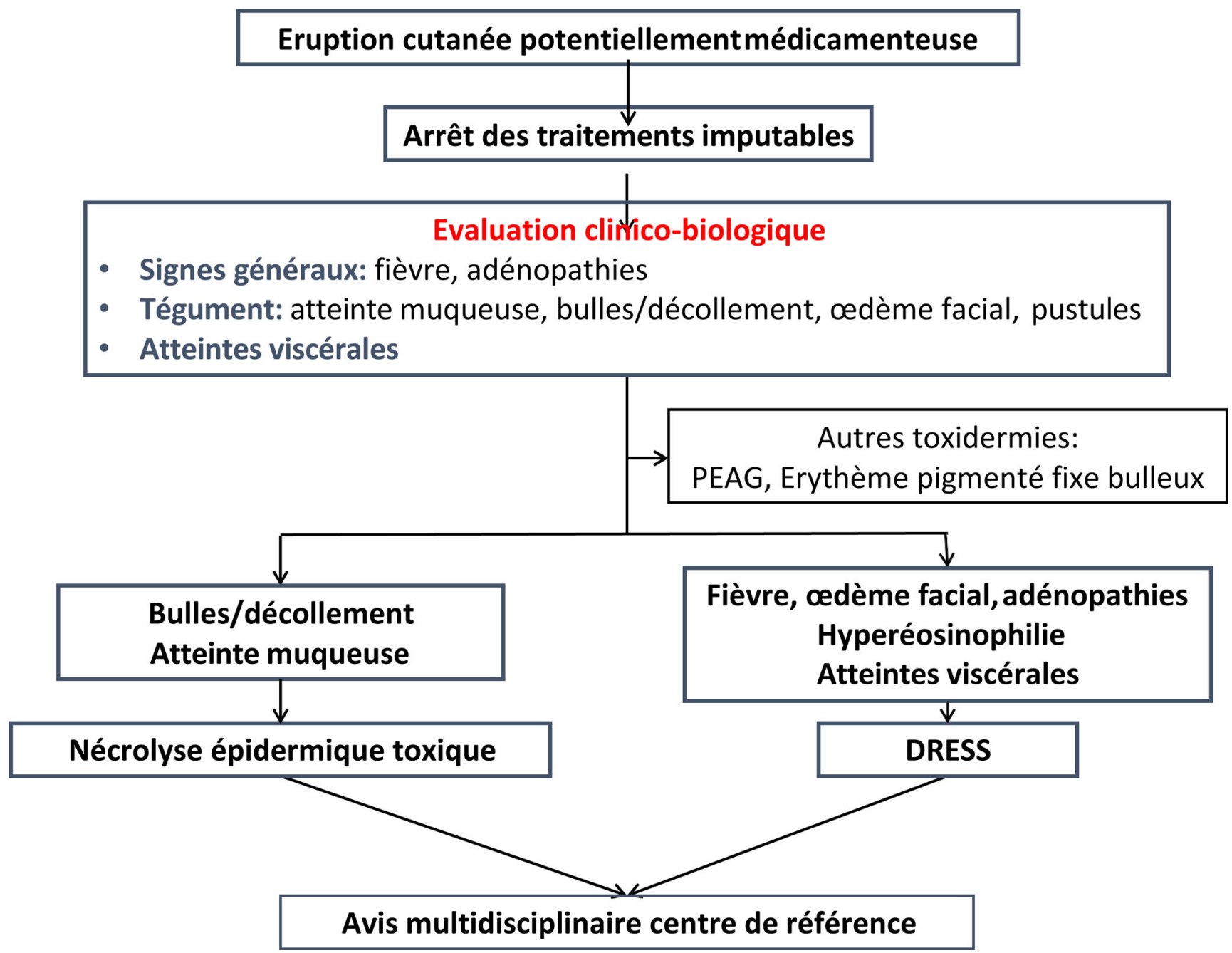

Fig. 3 Algorithme diagnostique simplifié des principales toxidermies graves (adapté de Duong et al. [47]). PEAG : pustulose exanthématique aiguë généralisée ; DRESS : drug reaction with eosinophilia and systemic symptoms 


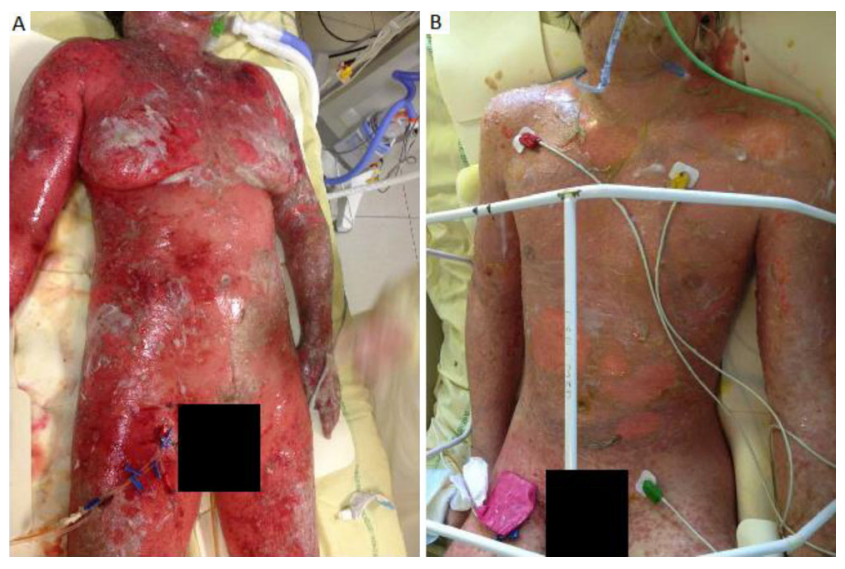

Fig. 4 Aspect cutané typique de nécrolyse épidermique toxique. A. Décollement cutané de l'ensemble du tégument réalisant un tableau de défaillance cutanée aiguë. Le derme est entièrement exposé. B. Décollement épidermique avec aspect « en linge mouillé » typique de la nécrolyse épidermique toxique

cardiaque), métaboliques (pertes hydriques et électrolytiques importantes, augmentation du métabolisme basal, notamment par altération de la thermorégulation) et enfin infectieuses avec une altération de la fonction barrière mais également une immunodépression systémique (lymphopénie, neutropénie).

Les principales mesures à initier à la phase aiguë sont résumées dans le tableau 3. L'arrêt immédiat de tout médicament imputable est la principale mesure thérapeutique ayant démontré un effet positif sur le pronostic des patients. Les soins de support incluent la correction des pertes liquidiennes et des troubles hydroélectrolytiques, une nutrition entérale précoce, le maintien d'une température ambiante comprise entre 28 et $32{ }^{\circ} \mathrm{C}$ afin de limiter l'hypercatabolisme associé aux pertes caloriques cutanées, une analgésie et une anxiolyse $[46,50]$. Environ $25 \%$ des patients développeront des défaillances d'organes, hémodynamique et respiratoire principalement, dont la prise en charge sera identique à celle des autres patients de réanimation. L'épuration extrarénale est nécessaire chez $10 \%$ des patients environ, associée à un pronostic particulièrement sombre [51].

Aucun traitement immunomodulateur n'a fait la preuve de son efficacité dans les SJS/NET. Le seul traitement évalué dans le cadre d'un essai randomisé contrôlé est le thalidomide, avec une surmortalité dans le groupe interventionnel et un arrêt précoce de l'essai [46,52]. L'utilisation des corticoïdes (hors choc septique) est controversée et, en l'absence de donnée convaincante, n'est pas recommandée. De même, les IgIV n'ont jamais été évaluées dans le cadre d'essais contrôlés. La ciclosporine orale est une molécule potentiellement intéressante, mais là encore, les données sont controversées [53-55].
Tableau 3 Prise en charge initiale des nécrolyses épidermiques (syndromes de Lyell et Stevens-Johnson, d'après IngenHousz-Oro S et al. [50])

\section{Principes de prise en charge initiale des nécrolyses} épidermiques

\section{Mesures générales}

Arrêt immédiat de tout médicament inutile ou imputable Pas d'administration prophylactique de médicament Pas de consensus sur un traitement spécifique

\section{Traitement de la défaillance cutanée}

Apports hydroélectrolytiques : formule de Brooke modifiée $(\mathrm{j} 1)^{\mathrm{a}}$ puis réévaluation quotidienne multiparamétrique ${ }^{\mathrm{b}}$ Nutrition entérale précoce

Maintien d'une température ambiante entre 28 et $32{ }^{\circ} \mathrm{C}$ Pas d'intérêt démontré à la perfusion systématique d'albumine

Prise en charge des défaillances d'organes associées Analgésie-anxiolyse

\section{Prise en charge respiratoire}

Pas d'intubation systématique Indications intubation

Défaillances d'organes

Signes d'atteinte trachéobronchique spécifique ${ }^{c}$

Anesthésie générale (douleur non soulagée)

$\mathrm{Si}$ atteinte spécifique grave : désencombrement bronchique endoscopique répété

\section{Soins paramédicaux quotidiens}

Toilettes antiseptiques

Éviter les traumatismes cutanés, ne pas débrider la peau lésée : limiter les manipulations, pas de pansement adhésif Vaseline sur l'ensemble des zones de décollement et lubrification des muqueuses

Pansements hydrocellulaires ${ }^{\mathrm{d}}$

\section{Prévention et traitement des infections}

Isolement protecteur

Cartes bactériennes bihebdomadaires

Antibiothérapie ciblée ${ }^{\mathrm{e}}$

Antibiothérapie probabiliste couvrant les entérobactéries et les germes cutanés documentés

${ }^{\text {a }}$ Volume des 24 heures $=1,5 \mathrm{ml} / \mathrm{kg}$ par pourcentage de SC brûlée de cristalloïdes

${ }^{\mathrm{b}}$ Diurèse (objectif 0,5 à $1 \mathrm{ml} / \mathrm{kg}$ par heure), hémoconcentration biologique, évaluation hémodynamique

${ }^{\mathrm{c}}$ Signes respiratoires survenus dans les 48 heures de l'hospitalisation, atteinte laryngée, hypersécrétion bronchique

${ }^{\mathrm{d}}$ Limitent les forces de cisaillement, absorbent les exsudats

${ }^{\mathrm{e}}$ Foyer infectieux documenté, sepsis/choc septique, bactériémie 
- Soins locaux

Les soins cutanés quotidiens visent à réduire la survenue de complications infectieuses, mais doivent être réalisés de manière atraumatique, en évitant de débrider la peau détachable pour ne pas mettre à nu la lame basale. L'antisepsie peut être obtenue en pulvérisant sur la peau une solution de chlorhexidine diluée à $0,05 \%$. Les patients peuvent ensuite être enduits de vaseline pour améliorer leur confort et reposer sur des tapis de pansements hydrocellulaires permettant de limiter les forces de cisaillement sur la peau lésée et d'absorber les sécrétions. Les soins muqueux, notamment oculaires, sont fondamentaux pour limiter les séquelles à long terme : une application locale de vitamine A éventuellement associée à des collyres mouillants sans conservateurs est réalisée de façon pluriquotidienne [46,50]. Des traitements plus spécifiques sont en cours d'évaluation [56].

\section{- Prise en charge des infections}

Dans une cohorte monocentrique de 179 patients atteints de SJS/NET, dont $25 \%$ étaient pris en charge en réanimation, $27 \%$ développaient au moins un épisode bactériémique pendant l'hospitalisation [57]. Les bactériémies étaient pour moitié polymicrobiennes. On retrouvait dans $50 \%$ des cas du staphylocoque doré, puis, par fréquence décroissante, les bacilles à Gram négatif non fermentants, les entérobactéries et d'autres cocci à Gram positif. Le risque de bactériémie était fortement associé à l'étendue du décollement cutané, avec un risque majeur en cas de décollement supérieur à $30 \%$. La réalisation de cartes bactériennes cutanées permet de monitorer la colonisation bactérienne cutanée et, dans une certaine mesure, d'apprécier le risque de survenue d'une bactériémie à un germe donné pour ainsi adapter l'antibiothérapie probabiliste. En effet, leurs valeurs prédictives négatives pour prédire l'absence de survenue d'une bactériémie à Pseudomonas spp. ou à staphylocoque doré étaient supérieures à $90 \%$ [57].

La question de l'initiation d'une antibiothérapie est difficile chez ces patients qui sont presque toujours fébriles à la phase aiguë. En règle générale, on débutera une antibiothérapie en cas de sepsis/choc septique ou d'infection documentée. L'antibiothérapie probabiliste doit couvrir les germes présents sur les cartes bactériennes cutanées et les entérobactéries du fait de la possibilité de translocation bactérienne à la fois cutanée et digestive, notamment en cas d'atteinte muqueuse [58].

- Prise en charge de l'atteinte respiratoire

Le risque de recours à la ventilation mécanique des patients atteints de NET est fortement associé au pourcentage de surface cutanée décollée et s'accompagne d'un pronostic som- bre [59]. Aux indications habituelles d'intubation orotrachéale (détresse respiratoire, choc, coma), il faut rajouter la nécessité de sédation en cas de douleur non contrôlée ainsi que les signes directs ou indirects d'atteinte trachéobronchique spécifique $[59,60]$. Les patients présentant des signes évocateurs de lésions épithéliales trachéobronchiques spécifiques (hypersécrétion bronchique avec difficulté à drainer les sécrétions, atteinte laryngée en nasofibroscopie, dyspnée et hypoxémie dans les 48 heures du diagnostic) sont à haut risque d'insuffisance respiratoire aiguë et doivent être surveillés dans une unité de réanimation spécialisée. Il faut probablement les intuber précocement du fait du risque d'obstruction des voies aériennes supérieures et d'intubation difficile. Il est important de noter que l'atteinte bronchique spécifique peut exister sans hypoxémie ou anomalie radiologique initiale. En pratique, une endoscopie bronchique est réalisée systématiquement chez les patients intubés pour rechercher une atteinte trachéobronchique spécifique. Des désobstructions endoscopiques régulières (aspiration des lambeaux de muqueuse bronchique et des sécrétions) seront réalisées pour les formes les plus graves pour prévenir le risque d'atélectasie aiguë. Des complications pulmonaires non spécifiques (infection pulmonaire, inhalation, atélectasies) sont également fréquentes, même en l'absence d'atteinte trachéobronchique spécifique.

\section{Drug reaction with eosinophilia and systemic symptoms}

\section{Diagnostic}

Le DRESS survient deux à six semaines après exposition médicamenteuse. Le diagnostic de DRESS est souvent plus difficile que celui des SJS/NET, et les patients peuvent être admis en réanimation pour des défaillances d'organes sans étiologie identifiée [61]. Il associe de façon inconstante et évolutive des atteintes viscérales, une éruption cutanée et des anomalies biologiques (Tableau 4). Globalement, il faut évoquer le diagnostic de DRESS devant l'association d'une éruption cutanée dont l'aspect peut être très variable (œdème facial et rash sur plus de $50 \%$ de la surface corporelle sont présents dans environ $75 \%$ des cas) (Fig. 5), associée à une ou plusieurs atteintes d'organes (le plus souvent une hépatite cytolytique), une fièvre et des anomalies de la numération (hyperéosinophilie, présence de lymphocytes hyperbasophiles ou thrombopénie) et une réplication virale inconstante (HHV6, CMV, EBV) [63]. Il n'existe pas de test pathognomonique, et les scores diagnostiques existants n'ont été développés que pour la validation rétrospective des diagnostics de DRESS. La mortalité en réanimation peut atteindre $47 \%$, principalement du fait des atteintes viscérales par infiltration éosinophilique ou lymphocytaire, essentiellement myocardiques, pulmonaires ou hépatiques, voire de syndromes d'activation macrophagique secondaires $[61,62]$. 
Tableau 4 Éléments diagnostiques du DRESS syndrome (adapté de Kardaun et al. [66]

Éruption cutanée suspectée secondaire à un médicament nécessitant une hospitalisation

$+\geq 3$ critères parmi $\quad$ Fièvre $\geq 38^{\circ} \mathrm{C}$

Adénopathies $\geq 2$ sites

Anomalies hématologiques

(éosinophilie, lymphocytose,

thrombopénie)

Atteinte d'organe (foie, rein, cœur)
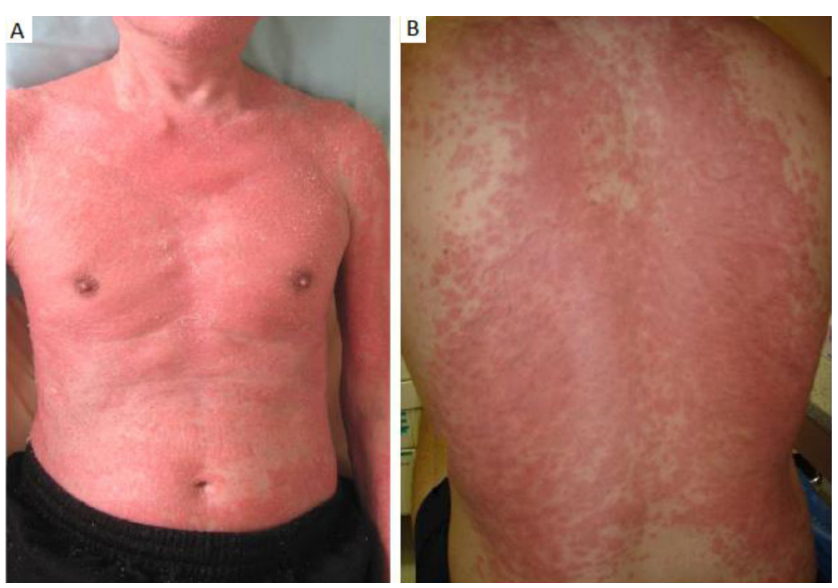

Fig. 5 Aspects cliniques évocateurs de DRESS syndrome. A. Érythrodermie à la phase aiguë d'un DRESS. B. Éruption maculopapuleuse du dos

\section{Prise en charge}

La première intervention thérapeutique consiste à arrêter dès que possible le ou les médicament(s) imputable(s). En l'absence d'atteinte viscérale, l'application de dermocorticoïdes permettra une amélioration rapide des symptômes cutanés [50]. La corticothérapie générale est indiquée dans les formes avec atteinte viscérale sévère [64]. Le traitement par IgIV n'est pas indiqué, le seul essai prospectif dans le DRESS ayant été interrompu précocement du fait d'effets secondaires graves dans le groupe interventionnel [65]. L'utilisation d'autres immunosuppresseurs n'a fait l'objet que de descriptions de cas isolés et ne peut donc être recommandée [60]. Les réactivations des virus du groupe herpès, notamment HHV6, classiques dans le DRESS, sont majorées par l'utilisation de corticoïdes systémiques. L'absence de données suffisantes concernant l'intérêt des antiviraux et leur potentielle toxicité limitent leur utilisation [67]. Le DRESS peut avoir une évolution biphasique, même en l'absence de réintroduction des traitements incriminés [68].
La prise en charge en réanimation des formes graves de DRESS doit intégrer la recherche et la prise en charge des défaillances d'organes, notamment hépatique, myocardique et rénale, principales pourvoyeuses de mortalité.

L'atteinte cardiaque recouvre un large spectre d'anomalies allant jusqu'à la myocardite fulminante avec choc cardiogénique, voire mort subite [69]. Elle peut survenir jusqu'à quatre mois après l'éruption cutanée et doit faire l'objet d'un dépistage systématique. L'électrocardiogramme peut mettre en évidence des troubles de la repolarisation ou de la conduction aspécifiques. Une élévation des biomarqueurs (troponine, BNP) est fréquente. L'échocardiographie peut mettre en évidence une dysfonction systolique monoou biventriculaire, un épaississement septal et un épanchement péricardique parfois de grande abondance. On discutera la réalisation d'une IRM cardiaque, voire d'une biopsie endomyocardique pour conforter le diagnostic. Le traitement, outre l'immunosuppression, peut nécessiter l'assistance cardiaque, et une surveillance au long cours est nécessaire du fait d'un risque élevé de rechute [70].

L'hépatite du DRESS, parfois associée à une hépatomégalie, peut entraîner un tableau biologique allant de la cytolyse modérée à l'hépatite cytolytique grave avec insuffisance hépatocellulaire, voire réaliser un authentique tableau d'hépatite fulminante. Dans ces formes sévères, l'efficacité de la corticothérapie n'est pas prouvée, et le DRESS peut récidiver en post-transplantation [71].

L'atteinte respiratoire, présente dans $15 \%$ des cas, peut aller de la simple toux à une véritable pneumonie à éosinophiles, parfois responsable d'une détresse respiratoire aiguë.

Une atteinte rénale de type néphrite interstitielle n'est pas rare. Enfin, l'apparition de cytopénies dans un contexte fébrile doit faire évoquer un syndrome d'activation macrophagique et faire discuter la réalisation d'un myélogramme. Tous les organes (système nerveux, pancréas, etc.) peuvent être atteints [67]. Les formes avec atteinte viscérale grave doivent être traitées par corticothérapie systémique avec décroissance très progressive compte tenu du risque de rechute [50].

\section{Conclusion}

Les urgences dermatologiques nécessitant une prise en charge en réanimation doivent bénéficier d'une approche multidisciplinaire. Les infections nécrosantes de la peau et des parties molles et les toxidermies graves sont des affections rares, voire très rares, leur diagnostic est difficile et leur pronostic vital et fonctionnel est sombre. Un tableau clinique évocateur d'infection de la peau et des parties molles associée à des défaillances d'organes impose d'éliminer une infection nécrosante, même en l'absence de signe cutané de nécrose évident. Seule l'exploration chirurgicale permettra 
de porter un diagnostic de certitude ; celle-ci ne doit pas être retardée par la réalisation d'examens complémentaires peu performants lorsque des signes de gravité systémiques sont présents. Les principaux facteurs pronostiques modifiables sont la précocité du débridement chirurgical et l'initiation d'une antibiothérapie probabiliste à large spectre.

Les nécrolyses épidermiques sont associées à une mortalité élevée, essentiellement secondaire aux complications infectieuses et pulmonaires, et à un risque de séquelles fonctionnelles, principalement oculaires, élevé. L'arrêt du ou des traitement(s) imputable(s) est la première mesure thérapeutique à mettre en œuvre. La gravité du DRESS est liée aux atteintes d'organes, notamment cardiaque et hépatique, qui doivent être systématiquement dépistées et conditionneront la mise en route d'un traitement immunosuppresseur.

Dans tous les cas, le recours à une expertise locale, régionale, via, par exemple, des centres de recours ou des centres ayant développé une filière dédiée à la prise en charge de ces patients spécifiques, ou nationale, par l'intermédiaire du Centre national de référence maladie rare des dermatoses bulleuses toxiques (https://fimarad.org/le-centre-de-referencedes-dermatoses-bulleuses-toxiques-et-toxidermies-graves/) est recommandé afin de proposer une prise en charge optimale aux patients.

Liens d'intérêts : les auteurs déclarent ne pas avoir de lien d'intérêt.

\section{Références}

1. George SMC, Harrison DA, Welch CA, Nolan KM, Friedmann PS, (2008) Dermatological conditions in intensive care: a secondary analysis of the Intensive Care National Audit and Research Centre (ICNARC) Case Mix Programme database. Crit Care Lond Engl 12: S1

2. Stevens DL, Bryant AE, (2017) Necrotizing soft-tissue infections. N Engl J Med 377: 2253-2265

3. Soltani AM, Best MJ, Francis CS, Allan BJ, Askari M, Panthaki ZJ, (2014) Trends in the incidence and treatment of necrotizing soft tissue infections: an analysis of the national hospital discharge survey. J Burn Care Res 35: 449-454

4. Van Stigt SFL, de Vries J, Bijker JB, Mollen RMHG, Hekma EJ, Lemson SM, Tan ECTH, (2016) Review of 58 patients with necrotizing fasciitis in the Netherlands. World J Emerg Surg 11: 21

5. Nuwayhid ZB, Aronoff DM, Mulla ZD, (2007) Blunt trauma as a risk factor for group A streptococcal necrotizing fasciitis. Ann Epidemiol 17: 878-881

6. Nicot R, Hippy C, Hochart C, Wiss A, Brygo A, Gautier S, Caron J, Ferri J, Raoul G, (2013) Les anti-inflammatoires aggravent-ils les cellulites faciales d'origine dentaire ? Rev Stomatol Chir Maxillo-Fac Chir Orale 114: 304-309

7. Weng TC, Chen CC, Toh HS, Tang HJ, (2011) Ibuprofen worsens Streptococcus pyogenes soft tissue infections in mice. J Microbiol Immunol Infect 44: 418-423

8. Brun-Buisson CJ, Saada M, Trunet P, Rapin M, Roujeau JC, Revuz J, (1985) Haemolytic streptococcal gangrene and nonsteroidal anti-inflammatory drugs. BMJ 290: 1786
9. Hua C, Sbidian E, Hemery F, Decousser JW, Bosc R, Amathieu R, Rahmouni A, Wolkenstein P, Valeyrie-Allanore L, Brun-Buisson C, de Prost N, Chosidow O, (2015) Prognostic factors in necrotizing soft-tissue infections (NSTI): a cohort study. J Am Acad Dermatol 73: 1006-1012.e8

10. Gelbard RB, Ferrada P, Yeh DD, Williams B, Loor M, Yon J, Mentzer C, Khwaja K, Khan M, Kohli A, Bulger EM, Robinson BRH, (2018) Optimal timing of initial debridement for necrotizing soft tissue infection: a practice management guideline from the Eastern Association for the Surgery of Trauma. J Trauma Acute Care Surg 85: 208-214. doi: 10.1097/TA.0000000000001857

11. Kiat HJ, En Natalie YH, Fatimah L, (2017) Necrotizing fasciitis: how reliable are the cutaneous signs? J Emerg Trauma Shock 10: 205-210

12. Kwak YG, Choi SH, Kim T, Park SY, Seo SH, Kim MB, Choi SH, (2017) Clinical guidelines for the antibiotic treatment for community-acquired skin and soft tissue infection. Infect Chemother 49: 301

13. Hietbrink F, Bode LG, Riddez L, Leenen LPH, van Dijk MR, (2016) Triple diagnostics for early detection of ambivalent necrotizing fasciitis. World J Emerg Surg 11: 51. eCollection 2016. doi: 10.1186/s13017-016-0108-z

14. Gunaratne DA, Tseros EA, Hasan Z, Kudpaje AS, Suruliraj A, Smith MC, Riffat F, Palme CE, (2018) Cervical necrotizing fasciitis: systematic review and analysis of 1,235 reported cases from the literature. Head Neck. doi: 10.1002/hed.25184 [Epub ahead of print]

15. Wong CH, Khin LW, Heng KS, Tan KC, Low CO, (2004) The LRINEC (Laboratory Risk Indicator for Necrotizing Fasciitis) score: a tool for distinguishing necrotizing fasciitis from other soft tissue infections. Crit Care Med 32: 1535-1541

16. Neeki M, Dong F, Au C, Toy J, Khoshab N, Lee C, Kwong E, Yuen H, Lee J, Ayvazian A, Lux P, Borger R, (2017) Evaluating the laboratory risk indicator to differentiate cellulitis from necrotizing fasciitis in the emergency department. West J Emerg Med 18: 684-689

17. Simonart T, Nakafusa J, Narisawa Y, (2004) The importance of serum creatine phosphokinase level in the early diagnosis and microbiological evaluation of necrotizing fasciitis. J Eur Acad Dermatol Venereol 18: 687-690

18. Murphy G, Markeson D, Choa R, Armstrong A, (2013) Raised serum lactate: a marker of necrotizing fasciitis? J Plast Reconstr Aesthet Surg 66: 1712-1716

19. Rahmouni A, Chosidow O, Mathieu D, Gueorguieva E, Jazaerli N, Radier C, Faivre JM, Roujeau JC, Vasile N, (1994) MR imaging in acute infectious cellulitis. Radiology 192: 493-496

20. Kim KT, Kim YJ, Won Lee J, Kim YJ, Park SW, Lim MK, Suh $\mathrm{CH}$, (2011) Can necrotizing infectious fasciitis be differentiated from nonnecrotizing infectious fasciitis with MR imaging? Radiology 259: 816-824

21. Goh T, Goh LG, Ang CH, Wong CH, (2014) Early diagnosis of necrotizing fasciitis: early diagnosis of necrotizing fasciitis. Br J Surg 101: e119-e125

22. Stevens DL, Bisno AL, Chambers HF, Dellinger EP, Goldstein EJC, Gorbach SL, Hirschmann JV, Kaplan SL, Montoya JG, Wade JC, (2014) Practice guidelines for the diagnosis and management of skin and soft tissue infections: 2014 update by the Infectious Diseases Society of America. Clin Infect Dis 59: e10-e52

23. Elliott DC, Kufera JA, Myers RA, (1996) Necrotizing soft tissue infections. Risk factors for mortality and strategies for management. Ann Surg 224: 672-683

24. Saeed K, Esposito S, Gould I, Ascione T, Bassetti M, Bonnet E, Bouza E, Chan M, Davis JS, De Simone G, Dryden M, Gottlieb T, Hijazi K, Lye DC, Pagliano P, Petridou C, Righi E, Segreti J, Unal S, Yalcin AN, (2018) Hot topics in necrotising skin and soft tissue infections. Int J Antimicrob Agents. doi: 10.1016/j. ijantimicag.2018.02.012 [Epub 2018 Mar 6] 
25. Brook I, Frazier EH, (1995) Clinical and microbiological features of necrotizing fasciitis. J Clin Microbiol 33: 2382-2387

26. Henri Mondor Hospital Necrotizing Fasciitis Group; de Prost N, Sbidian E, Chosidow O, Brun-Buisson C, Amathieu R, (2015) Management of necrotizing soft tissue infections in the intensive care unit: results of an international survey. Intensive Care Med 41: $1506-1508$

27. Holena DN, Mills AM, Carr BG, Wirtalla C, Sarani B, Kim PK, Braslow BM, Kelz RR, (2011) Transfer status: a risk factor for mortality in patients with necrotizing fasciitis. Surgery 150: 363-370

28. Burnham JP, Kirby JP, Kollef MH, (2016) Diagnosis and management of skin and soft tissue infections in the intensive care unit: a review. Intensive Care Med 42: 1899-1911

29. El-Menyar A, Asim M, Mudali IN, Mekkodathil A, Latifi R, AlThani H, (2017) The Laboratory Risk Indicator for Necrotizing Fasciitis (LRINEC) scoring: the diagnostic and potential prognostic role. Scand J Trauma Resusc Emerg Med 25: 28. doi: 10.1186/s13049-017-0359-Z

30. Bernal NP, Latenser BA, Born JM, Liao J, (2012) Trends in 393 necrotizing acute soft tissue infection patients 2000-2008. Burns 38: 252-260

31. Audureau E, Hua C, de Prost N, Hemery F, Decousser JW, Bosc R, Lepeule R, Chosidow O, Sbidian E; the Henri Mondor Hospital Necrotizing Fasciitis Group, (2017) Mortality of necrotizing fasciitis: relative influence of individual and hospital-level factors, a nationwide multilevel study, France, 2007-12. Br J Dermatol 177: 1575-1582

32. Ingraham AM, Jung HS, Liepert AE, Warner-Hillard C, Greenberg CC, Scarborough JE, (2017) Effect of transfer status on outcomes for necrotizing soft tissue infections. J Surg Res 220: 372-378

33. Brengard-Bresler T, De Runz A, Bourhis F, Mezzine H, Khairallah G, Younes M, Brix M, Simon E, (2017) Postoperative quality of life of patients with a bacterial necrotizing dermis-hypodermitis or necrotizing fasciitis, a ten-year study. Ann Chir Plast Esthet 62: $31-44$

34. SPILF; SFD, (2000) Conférence de consensus. Érysipèle et fasciite nécrosante : prise en charge. Med Mal Inf 30: 241-245

35. Sriskandan S, McKee A, Hall L, Cohen J, (1997) Comparative effects of clindamycin and ampicillin on superantigenic activity of Streptococcus pyogenes. J Antimicrob Chemother 40: 275-277

36. Carapetis JR, Jacoby P, Carville K, Ang SJJ, Curtis N, Andrews $R$, (2014) Effectiveness of clindamycin and intravenous immunoglobulin, and risk of disease in contacts, in invasive group a streptococcal infections. Clin Infect Dis 59: 358-365

37. Darenberg J, Ihendyane N, Sjölin J, Aufwerber E, Haidl S, Follin P, Andersson J, Norrby-Teglund A; StreptIg Study Group, (2003) Intravenous immunoglobulin $G$ therapy in streptococcal toxic shock syndrome: a European randomized, double-blind, placebocontrolled trial. Clin Infect Dis 37: 333-340

38. Linner A, Darenberg J, Sjolin J, Henriques-Normark B, NorrbyTeglund A, (2014) Clinical efficacy of polyspecific intravenous immunoglobulin therapy in patients with streptococcal toxic shock syndrome: a comparative observational study. Clin Infect Dis 59: $851-857$

39. Kaul R, McGeer A, Norrby-Teglund A, Kotb M, Schwartz B, O'Rourke K, Talbot J, Low DE, (1999) Intravenous immunoglobulin therapy for streptococcal toxic shock syndrome - a comparative observational study. Clin Infect Dis 28: 800-807

40. Kadri SS, Swihart BJ, Bonne SL, Hohmann SF, Hennessy LV, Louras P, Evans HL, Rhee C, Suffredini AF, Hooper DC, Follmann DA, Bulger EM, Danner RL, (2017) Impact of intravenous immunoglobulin on survival in necrotizing fasciitis with vasopressor-dependent shock: a propensity score-matched analysis from 130 US hospitals. Clin Infect Dis 64: 877-885

41. Madsen MB, Hjortrup PB, Hansen MB, Lange T, NorrbyTeglund A, Hyldegaard O, Perner A, (2017) Immunoglobulin G for patients with necrotising soft tissue infection (INSTINCT): a randomised, blinded, placebo-controlled trial. Intensive Care Med 43: $1585-1593$

42. Shaw JJ, Psoinos C, Emhoff TA, Shah SA, Santry HP, (2014) Not just full of hot air: hyperbaric oxygen therapy increases survival in cases of necrotizing soft tissue infections. Surg Infect 15: 328-335

43. Massey PR, Sakran JV, Mills AM, Sarani B, Aufhauser DD, Sims CA, Pascual JL, Kelz RR, Holena DN, (2012) Hyperbaric oxygen therapy in necrotizing soft tissue infections. J Surg Res 177: $146-151$

44. Devaney B, Frawley G, Frawley L, Pilcher DV, (2015) Necrotising soft tissue infections: the effect of hyperbaric oxygen on mortality. Anaesth Intensive Care 43: 685-692

45. Yang D, Davies A, Burge B, Watkins P, Dissanaike S, (2018) Open-to-air is a viable option for initial wound care in necrotizing soft tissue infection that allows early detection of recurrence without need for painful dressing changes or return to operating room. Surg Infect 19: 65-70

46. Ingen-Housz-Oro S, Duong TA, Bensaid B, Bellon N, de Prost N, Lu D, Lebrun-Vignes B, Gueudry J, Bequignon E, Zaghbib K, Royer G, Colin A, Do-Pham G, Bodemer C, Ortonne N, Barbaud A, Fardet L, Chosidow O, Wolkenstein P; French National Reference Center for Toxic Bullous Dermatoses, (2018) Epidermal necrolysis French national diagnosis and care protocol (PNDS; protocole national de diagnostic et de soins). Orphanet J Rare Dis 13: 56

47. Wang YH, Chen CB, Tassaneeyakul W, Saito Y, Aihara M, Choon SE, Lee HY, Chang MM, Roa FD, Wu CW, Zhang J, Nakkam N, Konyoung P, Okamoto-Uchida Y, Man-Tung Cheung C, Huang J, Ji C, Cheng B, Chung-Yee Hui R, Chu CY, Chen YJ, Wu CY, Hsu CK, Chiu TM, Ho HC, Lin JY, Yang CH, Chang YC, Su SC, Wang CW, Chung WH; for the Asian Severe Cutaneous Adverse Reaction Consortium, (2018) The medication risk of Stevens-Johnson syndrome and toxic epidermal necrolysis in Asians: the major drug causality and comparison to the USA FDA Label. Clin Pharmacol Ther. doi: 10.1002/cpt.1071 [Epub ahead of print]

48. Duong TA, Valeyrie-Allanore L, Wolkenstein P, Chosidow O, (2017) Severe cutaneous adverse reactions to drugs. Lancet 390: 1996-2011

49. Bastuji-Garin S, Fouchard N, Bertocchi M, Roujeau JC, Revuz J, Wolkenstein P, (2000) SCORTEN: a severity-of-illness score for toxic epidermal necrolysis. J Invest Dermatol 115: 149-153

50. Ingen-Housz-Oro S, Duong TA, de Prost N, Colin A, Fardet L, Lebrun-Vignes B, Barbaud A, Chosidow O, Wolkenstein P; Centre de référence des dermatoses bulleuses toxiques et toxidermies graves et FISARD, (2018) Treatment of severe cutaneous adverse drug reactions. Ann Dermatol Venereol. doi: 10.1016/j. annder.2018.02.014 [Epub 2018 Apr 13]

51. Papo M, Valeyrie-Allanore L, Razazi K, Carteaux G, Wolkenstein P, Chosidow O, Brun-Buisson C, Mekontso Dessap A, de Prost N, (2017) Renal replacement therapy during Stevens-Johnson syndrome and toxic epidermal necrolysis: a retrospective observational study of 238 patients. Br J Dermatol 176: 1370-1372

52. Wolkenstein P, Latarjet J, Roujeau JC, Duguet C, Boudeau S, Vaillant L, Maignan M, Schuhmacher MH, Milpied B, Pilorget A, Bocquet H, Brun-Buisson C, Revuz J, (1998) Randomised comparison of thalidomide versus placebo in toxic epidermal necrolysis. Lancet Lond Engl 352: 1586-1589

53. Wang $\mathrm{CW}$, Yang LY, Chen $\mathrm{CB}$, Ho HC, Hung SI, Yang $\mathrm{CH}$, Chang CJ, Su SC, Hui RCY, Chin SW, Huang LF, Lin YYW, Chang WY, Fan WL, Yang CY, Ho JC, Chang YC, Lu CW, Chung WH, (2018) Randomized, controlled trial of TNF- $\alpha$ antagonist in CTL-mediated severe cutaneous adverse reactions. J Clin Invest 128: 985-996 
54. Poizeau F, Gaudin O, Le Cleach L, Duong TA, Hua C, Hotz C, Ingen-Housz-Oro S, Sbidian E, Zehou O, Colin A, de Prost N, Lebrun-Vignes B, Chosidow O, Wolkenstein P, Fardet L, (2018) Cyclosporine for epidermal necrolysis: absence of beneficial effect in a retrospective cohort of 174 patients-exposed/unexposed and propensity score-matched analyses. J Invest Dermatol. doi: 10.1016/j.jid.2017.12.034 [Epub 2018 Jan 31]

55. Valeyrie-Allanore L, Wolkenstein P, Brochard L, Ortonne N, Maître B, Revuz J, Bagot M, Roujeau JC, (2010) Open trial of ciclosporin treatment for Stevens-Johnson syndrome and toxic epidermal necrolysis: Ciclosporin for SJS and TEN. Br J Dermatol 163: 847-853

56. Pinna A, Nuvoli E, Blasetti F, Posadinu MA, Boscia F, (2017) Plasmapheresis, intravenous immunoglobulins, and autologous serum eyedrops in the acute eye complications of toxic epidermal necrolysis. Eur J Ophthalmol 27: 658-663

57. De Prost N, Ingen-Housz-Oro S, Duong TA, Valeyrie-Allanore L, Legrand P, Wolkenstein P, Brochard L, Brun-Buisson C, Roujeau JC, (2010) Bacteremia in Stevens-Johnson syndrome and toxic epidermal necrolysis: epidemiology, risk factors, and predictive value of skin cultures. Medicine 89: 28-36

58. Tocco-Tussardi I, Huss F, Presman B, (2017) Microbiological findings and antibacterial therapy in Stevens-Johnson syndrome/ toxic epidermal necrolysis patients from a Swedish Burn Center. J Cutan Pathol 44: 420-432

59. De Prost N, Mekontso-Dessap A, Valeyrie-Allanore L, Van Nhieu JT, Duong TA, Chosidow O, Wolkenstein P, BrunBuisson C, Maître B, (2014) Acute respiratory failure in patients with toxic epidermal necrolysis: clinical features and factors associated with mechanical ventilation. Crit Care Med 42: 118-128

60. De Prost N, Mekontso-Dessap A, Valeyrie-Allanore L, Maître B, (2013) Atteintes bronchopulmonaires au cours des toxidermies graves. Reanimation 22: 73-79

61. Kimmoun A, Dubois E, Perez P, Barbaud A, Levy B, (2013) Shock state: an unrecognized and underestimated presentation of drug reaction with eosinophilia and systemic symptoms. Shock 40: $387-391$
62. Eshki M, Allanore L, Musette P, Milpied B, Grange A, Guillaume JC, Chosidow O, Guillot I, Paradis V, Joly P, Crickx B, Ranger-Rogez S, Descamps V, (2009) Twelve-year analysis of severe cases of drug reaction with eosinophilia and systemic symptoms: a cause of unpredictable multiorgan failure. Arch Dermatol 145: 67-72. doi: 10.1001/archderm.145.1.67

63. Cacoub P, Musette P, Descamps V, Meyer O, Speirs C, Finzi L, Roujeau JC, (2011) The DRESS syndrome: a literature review. Am J Med 124: 588-597

64. Funck-Brentano E, Duong TA, Bouvresse S, Bagot M, Wolkenstein P, Roujeau JC, Chosidow O, Valeyrie-Allanore L, (2015) Therapeutic management of DRESS: a retrospective study of 38 cases. J Am Acad Dermatol 72: 246-252

65. Joly P, Janela B, Tetart F, Rogez S, Picard D, D'Incan M, Descamps V, Collet E, Roujeau JC, Musette P, (2012) Poor benefit/ risk balance of intravenous immunoglobulins in DRESS. Arch Dermatol 148: 543-544

66. Kardaun SH, Sidoroff A, Valeyrie-Allanore L, Halevy S, Davidovici BB, Mockenhaupt M, Roujeau JC, (2007) Variability in the clinical pattern of cutaneaous side-effects of drugs with systematic symptoms: does a DRESS syndrome really exist? BR J Dermatol 156(3): 609-611

67. Descamps V, Ranger-Rogez S, (2014) DRESS syndrome. Joint Bone Spine 81: 15-21

68. Tan SC, Chan GYL, (2016) Relapsing drug-induced hypersensitivity syndrome: Curr Opin Allergy Clin Immunol 16: 333-338

69. Thongsri T, Chularojanamontri L, Pichler WJ, (2017) Cardiac involvement in DRESS syndrome. Asian Pac J Allergy Immunol 35: $3-10$

70. Bourgeois GP, Cafardi JA, Groysman V, Hughey LC, (2012) A review of DRESS-associated myocarditis. J Am Acad Dermatol 66: e229-e236

71. Ichai P, Laurent-Bellue A, Saliba F, Moreau D, Besch C, Francoz C, Valeyrie-Allanore L, Bretagne SR, Boudon M, Antonini TM, Artru F, Pittau G, Roux O, Azoulay D, Levesque E, Durand F, Guettier C, Samuel D, (2017) Acute liver failure/injury related to drug reaction with eosinophilia and systemic symptoms: outcomes and prognostic factors. Transplantation 101: 1830-1837 